\title{
Exploration on the Compound Function of Exhibition Prop Design from the Semiology Perspective
}

\author{
Qian GONG \\ Hubei Institute of Fine Arts, Wuhan, China
}

\begin{abstract}
On the basis of the semiotic theory, the compositional structure of the form and content of the symbol system is interpreted, and the denotation and connotation of the concepts of exhibition props are clarified. Then, the design methods of exhibition props are studied, and the compound functions of exhibition props, like exhibition, space guidance and planning, space atmosphere creation, brand image strengthening and artistic presentation, are deeply analyzed, in order to explore new space for the exhibition prop design from the semiology perspective and provide the guidance for the present exhibition prop design practice.

KEYWORD: Semeiology; Exhibition Props; Compound Functions
\end{abstract}

\section{OVERVIEW ON SEMIOLOGY}

As an interdisciplinary methodology, semiology is becoming an important part of epistemology and methodology of the humanities in modern society, involving many humanities and social sciences. Design semiology is a new discipline which is developed based on the semiotic theory. It uses signifier and signified to guide the design and systematically analyzes the design methods with the semiotic system. Exhibition props play an increasing important role in the modern commercial and cultural exhibition space and its function also develops from the single bearing to the integration of multiple functions. The study of the compound functions of exhibition props from the semiology perspective can explore the semiotic method and design innovation in exhibition prop design, the position and role of symbols in the formation and transmission of the exhibition prop design schemes and the research trend of the exhibition design semiology

The semiotic system in semiology is composed of signifier (symbol form) and signified (symbol content). For exhibition props, they are not just the simple exhibition instruments with the bearing function. Now, the design process of those props is becoming the symbolic chain system composed by elements, symbols and symbol system. The exhibition prop designers become the creator of exhibition prop symbols. They internalize the design symbols to modelling, material, function and color for coding combination, so as to realize innovation.
They also form the design concepts in expressing the meanings of the design symbols and shape the unique design style.

\subsection{Signified}

In exhibition prop design, boards, booths, shelves and cabinets express their existence and properties to the visitors through their structures, shapes, materials, colors and locations. After the deep understanding, observation and thinking of the design theme, the appropriate design symbols are extracted. With several processing ways like cutting and processing and based on multiple functions of the props, the surface structure of the exhibition prop design, including modeling, material and color, is formed.

\subsection{Signifier}

In the design of exhibition prop works, signifier refers to the meaning structure generated based on the functional structure of the props. It constitutes the symbolic structure chain which can signify the specific concept and characteristic. This link makes the interpretation of symbol diversified and complex. It's associated with the design level of designers and the comprehension ability, customs and educational quality of visitors. Only in the similar cultural environment can the feedback and interaction between the exhibition prop design and the audience be smooth. The visitors look for the profound connotation of the design according to their own 
comprehension and pour their emotions and concepts in it to build a communication process of semiology.

\section{CONNOTATION AND DENOTATION OF EXHIBITION PROPS}

"Prop" is interpreted as the stage instrument needed for drama, movies and other shows. In the category of exhibition design, the instruments bearing the information and exhibits are all called exhibition prop. It's the background, stage and contrast of the exhibit and theme as well as the material and technical basis of exhibition. It's performed by placing, bearing, maintaining and hanging. It can also constitute the space image to create a unique visual atmosphere. Exhibition props are the material basis of exhibition, the link connecting exhibits, space and human as well as the bridge ensuring the successful information communication. It not only bears exhibits and expresses the exhibition information, but also conveys the exhibition image and affects exhibition space cutting, space form and space.

Exhibition prop is an important part of the exhibition space. The information or atmosphere what the exhibition space wants to express can be further presented and interpreted by exhibition prop. It not only ensures the successful communication of the exhibition information with visitors, but also highlights the theme of the space, cuts the space and guides the visitors. In the exhibition space, all props which can display the exhibits and information are known as exhibition props.

\section{COMPOUND FUNCTIONS OF EXHIBITION PROPS}

With the diversified demand of the exhibition space, the forms and functions of exhibition props are no longer limited to singly bearing the function of exhibit display. The fixed pattern has been changed according to the theme of the exhibition space and the best way to display exhibits. The design research of exhibition props from the semiology perspective meets the requirements of highlighting important exhibits, creating the space atmosphere and strengthening the brand image. The exhibit prop design makes the exhibition space own the unique nature, leaves the visits more profound impression and presents the vivid and lively exhibition effect.

When displaying the exhibits, exhibit props evolve from the simple exhibition function into an important part of the space. Designers integrate exhibition props and exhibition space to make the former become an important part of guiding the space planning and shaping the space focus. The artistic form and clever conception give exhibition props special artistic personality. The compound character of exhibition prop is the improvement and integration of its compound functions and the internal requirement of its continuous development and perfection as well.

\subsection{Exhibition Bearing Function of Exhibition Props}

The exhibition bearing function of exhibition props is reflected by holding exhibits in the exhibition space to intuitively present them and transmit the information. In the initial exhibition activities, the exhibition props in the space had the most basic function of bearing exhibits. In the past, the vendors spread a cloth on a table on the wayside to display the goods. The form was simple, but it indicated the most basic function of exhibition props. Designers always put the exhibits in the most suitable place according to their volume and importance. The bearing quantity and density of props must be determined according to the exhibition requirements. Different space themes have different requirements on the exhibition ways of props.

Similarly, the large bookshelves which are common in bookstores are made to be the open props according to the characteristics of boos and the reading demand of visitors to place a large number of books and magazines. The exhibition props are mostly shelves and countertops to achieve the purposes of exhibition and storage. Due to the high price of exhibits, the exhibition props in jewelry stores are often the closed cabinets, few but fine, in order to highlight the key areas and the display effect of exhibits.

\subsection{Space Guidance and Planning Function of Exhibition Props}

Space guidance and planning function of exhibition props means that the props in the exhibition space like exhibition boards play multiple functions of space segmentation, guidance, planning and emphasis, so as to achieve the compound functions of space shaping and exhibition prop design, convey the information to visitors and make them enjoy the visit.

In some exhibition spaces, exhibition props not only display the exhibits but also plan the whole space. Designers design the location, size and height of exhibition props in the space through managing the space and changing the forms of the props, in which the props are taken as the tool for dividing the space. For example, the exhibition board is used to divide the space into main exhibition areas and channels, thus creating the sense of rhythm and beauty and making the props play the role of guiding the visitors. Planning the space with the exhibition 
props can make the most of available space and integrate the design of props and design together to reflect the special charm of the exhibition space.

\subsection{The Function of Creating the Space Atmosphere of Exhibition Props}

The function of creating the space atmosphere of exhibition props is to create the suitable and aesthetic exhibition atmosphere which fits in with the exhibition information and the brand image through designing the shape and color of exhibition props and applying the multimedia.

In today's exhibition space, exhibition props are no longer just traditional exhibition booths or shelves, but customized according to the design theme and style of the space. Designers integrate the shape and color of props with exhibition contents and grasp the pattern, material, color and shadow of the space to design the exhibition props with the unified style and more lights, create the more charming and special exhibition space and show the exhibition them and space atmosphere with the multi-dimensional method. For example, the cartoon bookshelves made of wood are used to create the warm and peaceful atmosphere in the bookstore; the exhibition props in toy stores are made of soft materials in different colors to show the lively and lovely atmosphere.

\subsection{The Function of Strengthening the Brand Image of Exhibition Props}

The function of strengthening the brand image means that the exhibition prop design has become an important carrier for the businessmen to display their brand images. The brand and theme of the exhibition space can be strengthened through the unity of exhibition props and brand images of enterprises.

In modern exhibition cases, especially in the business exhibitions, the exhibition space has the distinctive brand characteristics and exhibition theme. In those cases with clear requirements on the style and theme, exhibition props play an important role. The creation and application of exhibition props increasingly involves the brand image and the additional meanings of its symbol. The brand image is perfectly embedded into the artistic props to vividly reflect the symbol image. Contemporary society has gradually entered a visual era, which not only stimulates the consumers' ways of viewing, but also affects their ways of life and consumption. And, in business activities, they always make a choice through the symbolic brands. The exhibition props with the brand marks distinguish themselves with other brand business spaces. Only when the props in the business exhibition space are highly unified with the theme, can they become a part of the brand image.

\subsection{Artistic Style Presentation of Exhibition Props}

The personalized style of exhibition props means the artistic styles of exhibition props change with the requirements of the exhibition contents in the exhibition space. Personalization of exhibition props ultimately promotes the unique space to express the complex information with the artistic forms. Artistic style is reflected by recognition and aesthetics. For recognition, it not only pursues the rhythm and beauty of the prop form, but also expresses rich brand connotation and meaning. Aesthetics is not only internalized in the organizational structure of the prop design, but also reflected in the symbolic form of props and the expression of its symbolic connotation.

Exhibition props also change with the exhibition form. Their roles are more and more diverse and unique. They are no longer the unified form and structure but the stylized ones. When designing those exhibition props, designers consider not only their bearing and exhibition capacities but also the formal sense: how to make the exhibition props both practical and beautiful and how to design the suitable exhibition props to make the space more wonderful. Thus, designers make the exhibition props more and more personalized and artistic through their understanding of the space theme and their feeling of the space atmosphere, thus upgrading the exhibition props from the auxiliary display function to the visual center in the space. Even in the absence of exhibits, the exhibition props still become the perfect works of art in the space through their own artistic images.

\section{CONCLUSION}

Nowadays, exhibition props are widely used in the exhibition design industry. However, design creation does not mean art creation. Exhibition props need to be presented according to the culture and the symbolic mining of industrial characteristics of the enterprise brand, characterize the core information of the brand and meet the necessary security, illumination, dimension and other technical requirements of the exhibits. The exhibition board, booth, shelf and cabinet should be designed with the space processing technique, in order to reflect their compound functions.

Exhibition props reflect their compound functions in multiple dimensions: from the perspective of exhibits, exhibition props are used to show off and beautify the products; from the perspective of design, exhibition props strengthen the brand image and highlight the advantages of the products; from the perspective of space design, exhibition props are used to plan the space, foil the space atmosphere and promote the integration between products and space. 
The main function of exhibition props is the deduction and conveying of the exhibition information. They are designed according to the theme of the exhibition activity, the size of the exhibition space and the volume of the exhibits. Exhibition props like cabinets and boards can be used to plan the space and highlight the key exhibition areas (like exhibition booth). When designing those exhibition props, the visiting time of the visitors is taken into account and the fourdimensional space-time rhythm is used to reflect multidimensional display information of the exhibition space like form and meaning \& reality and nihility, and create colorful visual effects and unforgettable experience process.

\section{REFERENCES}

[1] Gong Qian .The system of exhibition props research. Southwest China Normal University Press, 2015 